\title{
How to get better TAD? Relationship between anteversion angle of nail and position of femoral neck guide pin during nailing of intertrochanteric fractures
}

Zhe Wang ${ }^{1 \dagger}$, Yadong Liü ${ }^{2 \dagger}$, Shenglong Li ${ }^{3}$, Xiuhui Wang ${ }^{4}$, Changjian Li ${ }^{2^{*}}$ and Xin Tang ${ }^{2^{*}}$

\begin{abstract}
Background: To demonstrate the correlation between guide pin-shaft angle (PSA) at the anteroposterior film and anteversion angle of guide pin at the lateral film and investigate whether excellent tip-apex distance (TAD) can be obtained by changing the entry point via axial rotation of the main intramedullary nail.

Methods: Fifty patients with intertrochanteric femoral fractures (IFFs) undergoing internal fixation with intramedullary nails under 2D fluoroscopy were retrospectively enrolled. Both of the PSA at the anteroposterior film and anteversion angle at the lateral film before and after adjustment of the guide pin were collected. Pearson correlation analysis was performed to investigate their correlation. Intraoperative and postoperative outcomes were recorded. Furthermore, the software of Mimics 10.0 and Pro/E were used to establish the 3D models of the proximal femur and main intramedullary nail/guide pin, respectively. Surgery was simulated on the Pro/E software platform and solid geometry analysis was conducted to calculate the correlation between the PSA and the anteversion angle.
\end{abstract}

Results: Pearson correlation analysis indicated there was a positive correlation between PSA and anteversion angle, with the correlation coefficient of $0.902(p<0.01)$. By altering the PSA and anteversion angle, TAD was adjusted to be less than $25 \mathrm{~mm}$ in all patients. The mean operative time, fluoroscopy time and length of hospital stay were $65.82 \pm 11.16 \mathrm{~min}, 2.03 \pm 0.79 \mathrm{~min}$ and $6.66 \pm 2.49 \mathrm{~d}$. Thirty-one patients received blood transfusions $(3.55 \pm 1.95 \mathrm{U})$. Fracture reduction was considered to be good or acceptable in all patients. Complications occurred only in 6 patients (12.00\%). At a 3-month follow-up, the mean Timed Up and Go was $31.54 \pm 20.95 \mathrm{~s}$ and Harris Hip Score was $72.88 \pm 8.79$. The $3 \mathrm{D}$ surgery model also showed when the main intramedullary nail was externally rotated or internally rotated of $20^{\circ}$ at the standard location, the PSA of guide pin at the anteroposterior position and anteversion angle of the guide pin at the lateral position were simultaneously increased or decreased.

Conclusion: Our findings suggest altering the PSA and anteversion angle may be beneficial for obtaining excellent TAD and achieving superior outcomes.

Keywords: Intertrochanteric fracture, 3D modeling, Internal-fixation, Guide pin, Tip-apex distance, Pin-shaft angle

\footnotetext{
* Correspondence: changijianliu1225@126.com; 13704940088@163.com

'Zhe Wang and Yadong Liu contributed equally to this work.

${ }^{2}$ Department of Orthopedic Trauma, the First Affiliated Hospital of Dalian

Medical University, Dalian 116011, Liaoning Province, China

Full list of author information is available at the end of the article
}

(c) The Author(s). 2020 Open Access This article is licensed under a Creative Commons Attribution 4.0 International License, which permits use, sharing, adaptation, distribution and reproduction in any medium or format, as long as you give appropriate credit to the original author(s) and the source, provide a link to the Creative Commons licence, and indicate if changes were made. The images or other third party material in this article are included in the article's Creative Commons licence, unless indicated otherwise in a credit line to the material. If material is not included in the article's Creative Commons licence and your intended use is not permitted by statutory regulation or exceeds the permitted use, you will need to obtain permission directly from the copyright holder. To view a copy of this licence, visit http://creativecommons.org/licenses/by/4.0/ The Creative Commons Public Domain Dedication waiver (http://creativecommons.org/publicdomain/zero/1.0/) applies to the data made available in this article, unless otherwise stated in a credit line to the data. 


\section{Background}

Intertrochanteric femoral fractures (IFFs) are relatively common clinical injuries in elder people (especially aged over 65 years), accounting for approximately $50 \%$ of all hip fractures [1]. With the improvement of living standards, the increase of serious traffic accidents and the extension of human life, the incidence of IFFs is reported to be markedly rising, particularly in Asia [2]. It is estimated that the total number of hip fractures may annually exceed 0.5 million in 2030 and 1 million in 2050 in Asia [3]. Thus, how to manage IFFs has been a hot issue for orthopedic surgeons.

Currently, surgical intervention is recommended as the preferred treatment for IFFs except a few patients who had a very poor general condition and can't tolerate anesthesia and surgery. Generally, intramedullary [i.e. proximal femoral nail anti-rotation (PFNA), proximal femoral nail (InterTAN), Gamma nail] and extramedullary (i.e. dynamic hip screw, dynamic condylar screw) fixations are two primary options for surgical treatment of such fractures. Compared with extramedullary implants, less blood loss, mechanical complications and better functional scores can be achieved after intramedullary fixations $[4,5]$. Further comparisons between different intramedullary fixators indicate PFNA and InterTAN may be superior to Gamma nail to cause shorter operative time, length of hospital stay and less blood loss $[6,7]$, while a similar effect may be present between PFNA and InterTAN [8]. Therefore, intramedullary nail fixations with PFNA and InterTAN are the most widely used approaches for IFFs.

It has been a consensus that measuring the tipapex distance (TAD) on anteroposterior and lateral radiographs is a valuable tool to assist accurate placement of screws or nails for fixation of IFFs. The TAD should be less than 25 or $27 \mathrm{~mm}$ in order to reduce the complications of the cut-out and nail breakage, fracture non-union and poor functional outcomes [9-13]. However, intraoperative determination of TAD is difficult and can be hampered by
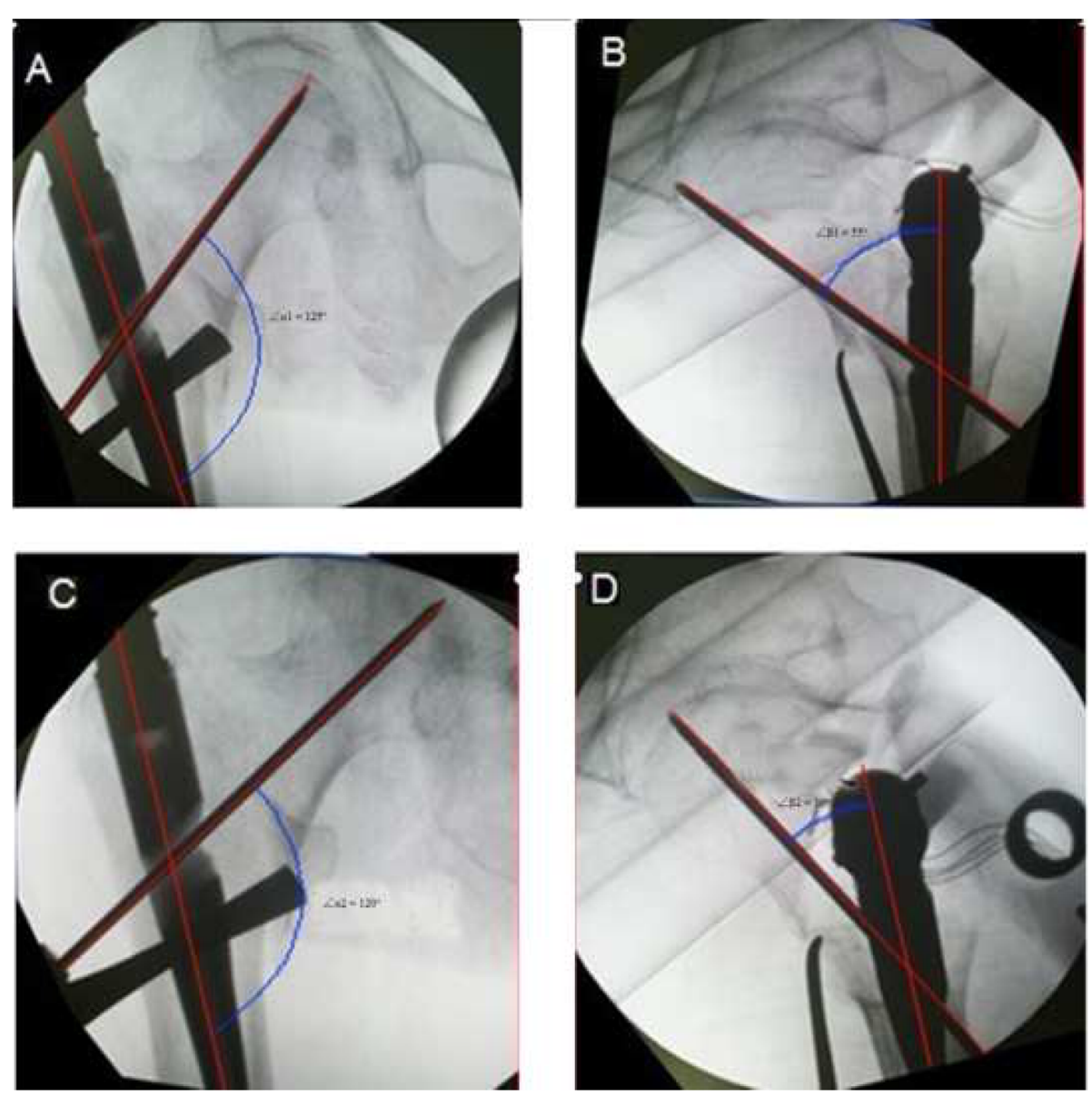

Fig. 1 The guide pin-shaft angle and anteversion before $(\mathbf{a}, \angle a 1 ; \mathbf{c}, \angle \beta 1)$ and after $(\mathbf{b}, \angle a 2 ; \mathbf{d}, \angle \beta 2)$ the adjustment of the guide pin measured for one included patient 
the image quality, body habitus and image projection $[14,15]$. The repetitive adjustment of the main intramedullary nail and guide pin under the $\mathrm{C}$-arm machine or a wide range of stripping and exposure may further increase the operative and fluoroscopy time and cause more complications and instability, especially for the surgeons who are lack of experience [16-19]. Hereby, how to quickly obtain this excellent TAD remains a challenging problem. In our clinical experience, we occasionally found an interesting phenomenon: there is a correlation between pinshaft angle (PSA, $\angle \alpha$, defined as the angle between the axis of the main femoral intramedullary nail and the axis of the screw guide pin of the femoral neck at the anteroposterior position) and anteversion angle ( $\angle \beta$, defined as the angle between the main axis of the femoral intramedullary nail and the axis of the screw guide pin of the femoral neck at the lateral position) when the main femoral intramedullary nail was rotated along the axis during the operation to adjust the location of femoral neck screw guide pin. With the main intramedullary nail keeping in constant depth, when the anteversion angle was increased, there was also an increase in the PSA,
A
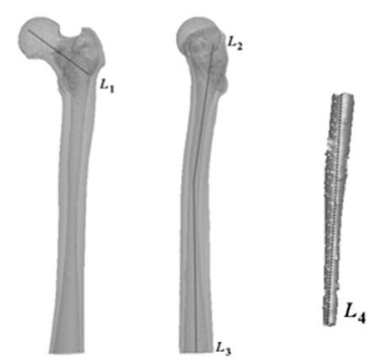

C
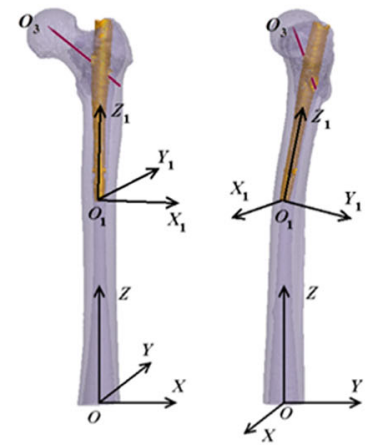

D

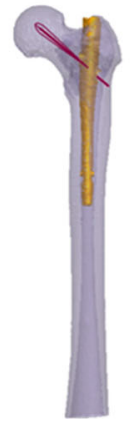

B
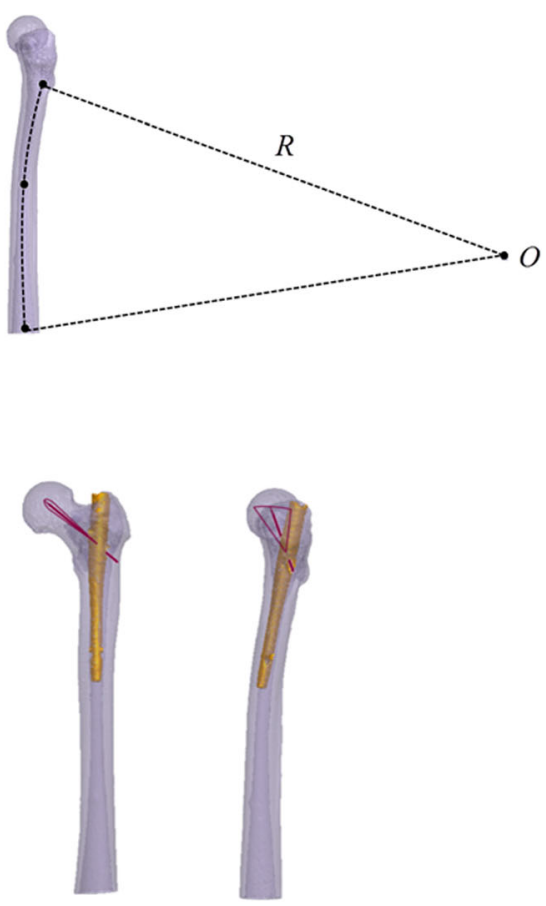

E
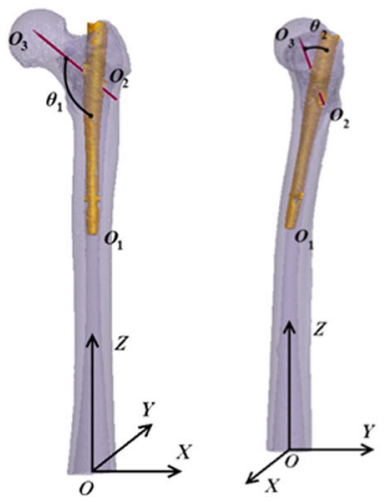

Fig. 2 Simulation operation and mathematical analysis. $\mathbf{a}$, femoral and intramedullary nail model; $\mathbf{b}$, measurement on curvature radius of femur; $\mathbf{C}$ fluoroscopycoordinate system O-XYZ, guide pin trajectory co-ordinate system O1-X1Y1Z1; $\mathbf{d}$, The plane of the femoral neck guide pin is within the scope of the red line; $\mathbf{e}$, calculation on PSA of and anteversion of guide pin 
which led to an elevated place of the guide pin in the head neck and caused the change in TAD. This provided an idea to regulate TAD by altering the PSA and anteversion angle.

In this study, we aimed to further quantize the correlation between the PSA and the anteversion angle using the imaging data of case series and assess whether altering the PSA and anteversion angle may be beneficial for obtaining excellent TAD and achieving superior intraoperative and postoperative outcomes. Furthermore, three-dimensional (3D) operation and mathematical simulations [20] were also used to establish a personalized distribution map of the femoral neck guide pin to guide the location adjustment for the femoral neck guide pin.

\section{Methods}

\section{Clinical trials}

Patients with IFFs who underwent closed reduction and internal fixation with femoral intramedullary nails under two-dimensional (2D) fluoroscopy in the Zhongshan Hospital, Fudan University, the First Affiliated Hospital of Dalian Medical University and Shanghai Pudong New District Zhoupu Hospital between March 2010 and October 2015, were retrospectively enrolled. Inclusion criteria were: (1) age > 65 years; (2) the time interval from the injury to admission $<24 \mathrm{~h}$; (3) intraoperative fracture end was well reset and the anatomical repositioning was generally achieved; (4) the position of the guide pin in the femoral neck was adjusted by changing the entry point via axial rotation of the main intramedullary nail; (5) the imaging data were completed; and (6)

Table 1 Demographics of 50 patients

\begin{tabular}{ll}
\hline & Patients \\
\hline Gender (female) & \\
Age (year) & $76.04 \pm 6.28$ \\
Side (left) & $28(56.00 \%)$ \\
Injury mechanism & \\
Traffic injury & $8(16.00 \%)$ \\
Falling injury & $42(34.00 \%)$ \\
AO type & \\
31 A2 & $46(92.00 \%)$ \\
31 A3 & $4(8.00 \%)$ \\
ASA & \\
1 & $1(2.00 \%)$ \\
2 & $23(46.00 \%)$ \\
3 & $25(50.00 \%)$ \\
4 & $1(2.00 \%)$ \\
\hline
\end{tabular}

Table 2 Operative records

\begin{tabular}{ll}
\hline & Data \\
\hline Operation time (min) & $65.82 \pm 11.16$ \\
Blood transfusion $(U)$ & $3.55 \pm 1.95$ \\
Fluoroscopy time $(\mathrm{s})$ & $2.03 \pm 0.79$ \\
Length of hospital stay $(\mathrm{d})$ & $6.66 \pm 2.49$ \\
Fracture reduction & \\
Good & $47(94.00 \%)$ \\
Acceptable & $3(6.00 \%)$ \\
Poor & 0 \\
$\angle a 1$ & $131.63 \pm 5.27$ \\
$\angle \beta 1$ & $26.69 \pm 7.36$ \\
$\angle a 2$ & $130.30 \pm 3.72$ \\
$\angle \beta 2$ & $21.55 \pm 3.84$ \\
TAD (mm) & $20.52 \pm 2.80$
\end{tabular}

TAD Tip-apex distance; The pin shaft angle and anteversion before $(\angle a 1, \angle \beta 1)$ and after $(\angle a 2, \angle \beta 2)$ the adjustment of the guide pin

unilateral closed fracture. Exclusion criteria included: (1) concurrent femoral fractures at other parts of the same side; (2) long-term wheelchair use before injury; (3) pathological IFFs; (4) old IFFs; (5) without fixed address or some subjective reasons not want to participate in the trials; and (6) incomplete follow-up information. This study was approved by the ethics committee of our institution.

All surgery in three centers was performed by the same senior surgeon under general, continuous epidural or nerve block anesthesia. The main intramedullary nail was placed into the proper location in the femoral shaft according to the standard surgical procedures: First, the guide pin was placed into the femoral neck, and non-ideal location of the guide pin was seen under fluoroscopy at the anteroposterior and lateral positions during the operation; Then, the main nail was rotated along its longitudinal axis to adjust the entry point of guide pin followed by replacement of the guide pin and observation under fluoroscopy. The length of the main intramedullary nail and mode of distal locking were determined according to the patients' condition. The location of the femoral neck guide pin was adjusted by axially rotating the main femoral intramedullary nail to alter the entry point and ensure the TAD not exceeding 25 $\mathrm{mm}$ [9-13]. The TAD was measured by three individual observers through $\mathrm{C}$-arm $\mathrm{x}$-ray intra-operatively. The rotation of the nail will not stop until guide pin is on an ideal position. So, the nail should be rotated slowly and steadily with the assistance of intraoperative $\mathrm{c}$-arm X-ray to decide the rotation of the nail. Meanwhile, the rotation angle of the nail was 

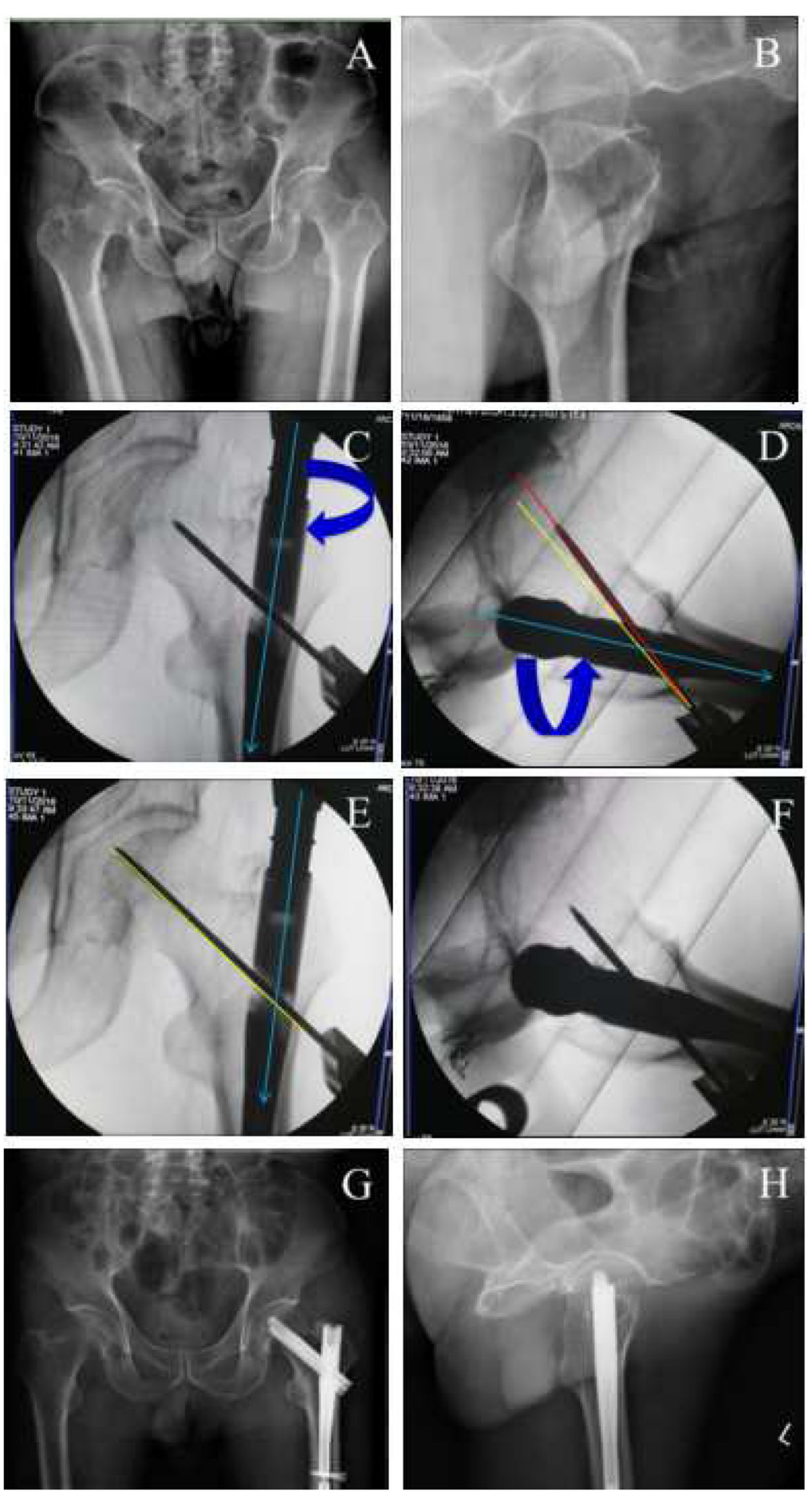

Fig. 3 (See legend on next page.) 
(See figure on previous page.)

Fig. 3 A typical case to regulate the PSA and anteversion angle to obtain ideal TAD. $\mathbf{a}-\mathbf{b}$, preoperative anteroposterior (a) and lateral (b) X-ray to diagnose intertaochanteric fractures; $\mathbf{c}-\mathbf{f}$, the adjustment of the guide pin. When position of neck guide pin is higher (the PSA is larger, $\mathbf{c}$ ) and anteversion angle of nail is more than normal (d), we need to internally rotate the nail to make anteversion angle smaller (f) (at the same time, the PSA will become less in AP view, e) to get better TAD; $\mathbf{g}$-h, postoperative anteroposterior ( $\mathbf{g})$ and lateral (h) X-ray to confirm the fracture reduction. Green line, nail position; red line, current position; yellow, ideal position

recorded based on the location change in pre- and post- rotation of T-shaped wrench. PSA and anteversion angle before $(\angle \alpha 1, \angle \beta 1)$ and after $(\angle \alpha 2, \angle \beta 2)$ the adjustment of the guide pin was respectively measured for all the included patients using professional drawing software on X-ray (Fig. 1). In order to reach a good reduction for the proximal femur, the intact opposite proximal femur was also $\mathrm{x}$-rayed preoperatively to provide a reference for reduction procedure during the surgery. The angle of the nail was chosen for fracture fixation based on neck-shaft angle from the opposite femur.

At $24 \mathrm{~h}$ after operation, patients were encouraged to walk with the aid of double crutches or walker. Partial weight-bearing was also allowed on the affected limb. Rivaroxaban was orally administered for 7 weeks to prevent thrombogenesis. The operative time (min), overall fluoroscopy time (min), blood loss during surgery, amount of transfused blood (U), length of hospital stay (d) and postoperative complications were recorded. The radiographs of the hip joints (anteroposterior position, bilateral; lateral position, the affected) were made to evaluate the fracture reduction at $24-48 \mathrm{~h}$ after operation. The quality of the fracture reduction was graded as poor ( $>10^{\circ}$ varus/valgus), acceptable $\left(5^{\circ}-10^{\circ}\right.$ varus/valgus $)$ or good $\left(<5^{\circ}\right.$ varus $/$ valgus) [21]. Functional outcome was assessed postoperatively, at 6-week and 3-month follow-up on the basis of the Timed Up and Go (TUG) test [22] and the Harris hip score (HHS) [23].

Data were expressed as mean \pm standard deviation or number (\%). Pearson correlation analysis was performed to investigate the correlation between the PSA at the anteroposterior position and anteversion angle of the guide pin at the lateral position. The level of statistical significance was set at a two-sided $p$-value $<0.05$.

\section{Simulation analysis}

Among the included patients, one patient was randomly selected to extract the raw computerized tomography (CT) data and establish the femoral and intramedullary nail geometric models. Data requirements included: (1) the patient underwent postoperative 64 slice spiral CT scan (GE company, USA), with the scan scope from the hip to the lower $1 / 3$ of the femur; (2) the slice gap of each scan was $1 \mathrm{~mm}$; (3) the density of pixel matrix was $512 \times 512$; and (4) 2 bytes were assigned for each pixel. The obtained CT images were stored in Dicom format. Patient's data in Dicom format were imported into Mimics 10.01 (Materialize company, Belgium). Through image positioning, threshold setting, dynamic area growth and hole filling, the redundant data were removed and the 3D visualization model of the femur (Fig. 2a) was rebuilt. According to PFNA intramedullary nailing data provided by SYNTHES (Switzerland), the intramedullary nail and guide pin models (Fig. 2a) were established using Pro/E 3.0 software. Models were exported in a lis format. The femoral shaft was bent to the anterolateral direction. Mimics 10.01 was used to draw the axis of the femoral marrow cavity, and the physical radian of the marrow cavity axis from the site of $2 \mathrm{~cm}$ under femoral intertrochanter to lower $1 / 3$ of the femur was measured and presented as curvature radius (R) (Fig. $2 \mathrm{~b})$. Detail processes of operation simulation and mathematical analysis (Fig. 2c-e) were described in Supplementary file 1 .

\section{Results}

\section{Clinical observation}

Fifty patients were included in this study (Table 1; Supplementary file 2), where $30(60 \%)$ cases were male and $20(40.0 \%)$ cases were female. Their age ranged from 60 to 85 years old, with an average of $76.04 \pm 6.28$ years old. All the patients suffered from IFFs with $28(56.00 \%)$ occurred on the left side and $22(44.00 \%)$ on the right side. Unstable trochanteric fractures were classified as $\mathrm{AO}-31 \mathrm{~A} 2$ in $46(92.00 \%)$ cases and $31 \mathrm{~A} 3$ in $4(8.00 \%)$ cases. All of the fractures were fresh closed fractures and were treated with closed reduction and internal fixation with femoral intramedullary nails.

PSA $(\angle \alpha)$ and anteversion angle $(\angle \beta)$ of the guide pin on intraoperative imaging were collected from these 50 clinical cases (Table 2) and then, Pearson correlation analysis was performed. In line with our occasionally seen results, there was indeed a significantly positive correlation between the PSA and the anteversion angle, with the correlation coefficient of $0.902(p<0.01)$. By altering the PSA and the 

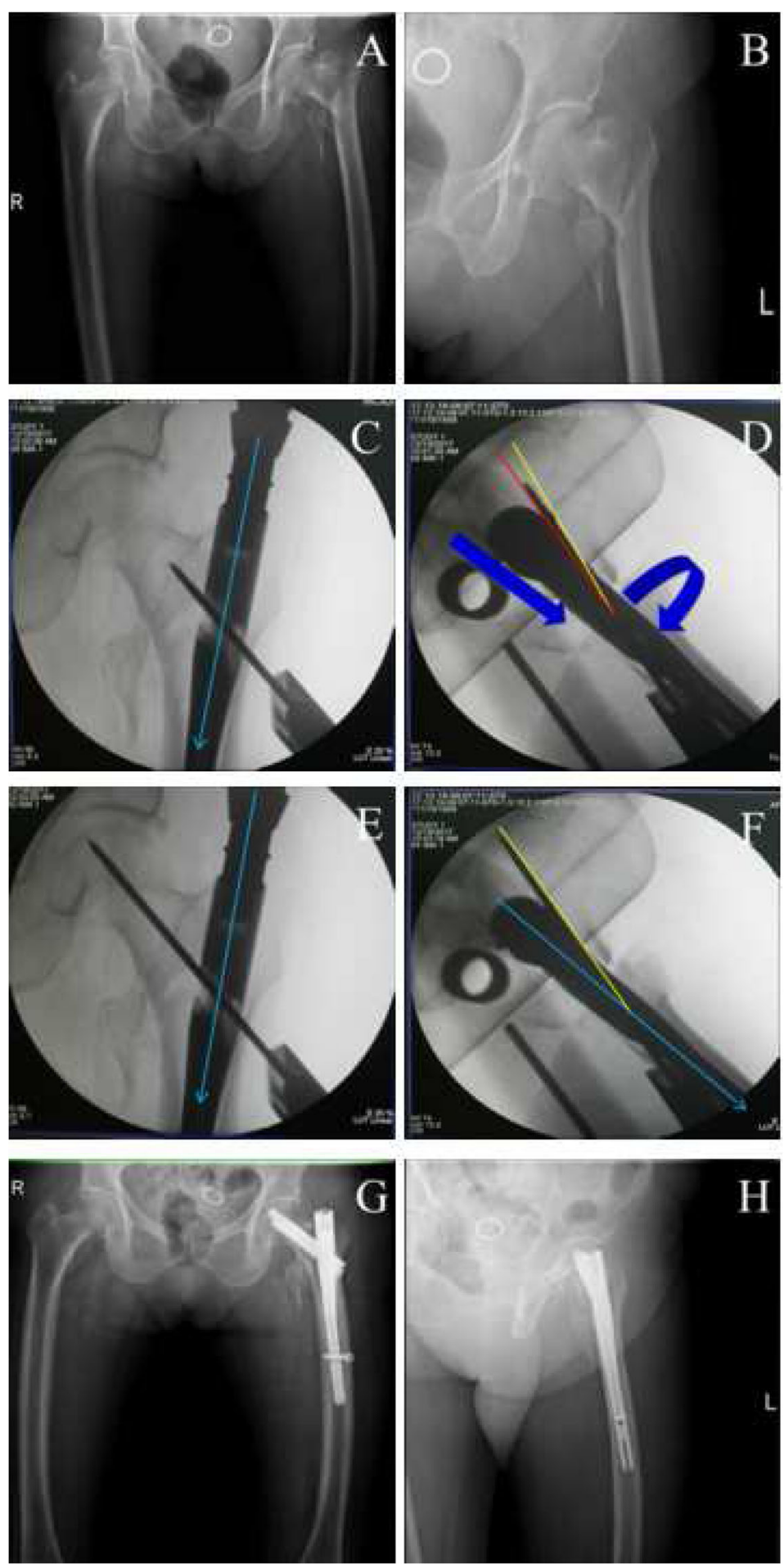

Fig. 4 (See legend on next page.) 
(See figure on previous page.)

Fig. 4 A typical case to regulate the PSA and anteversion angle to obtain ideal TAD. $\mathbf{a}$-b, preoperative anteroposterior (a) and lateral (b) X-ray to diagnose intertaochanteric fractures; $\mathbf{c}-\mathbf{f}$, the adjustment of the guide pin. When position of neck guide pin is higher (the PSA is larger, $\mathbf{c}$ ) than normal and anteversion angle is less than normal (d), we need to deepen the nail and externally rotate it to make antevertion angle bigger (f) (at the same time, the PSA will increase in AP view, e) to get better TAD; $\mathbf{g}-\mathbf{h}$, postoperative anteroposterior $(\mathbf{g})$ and lateral (h) X-ray to confirm the fracture reduction. Green line, nail position; red line, current position; yellow, ideal position
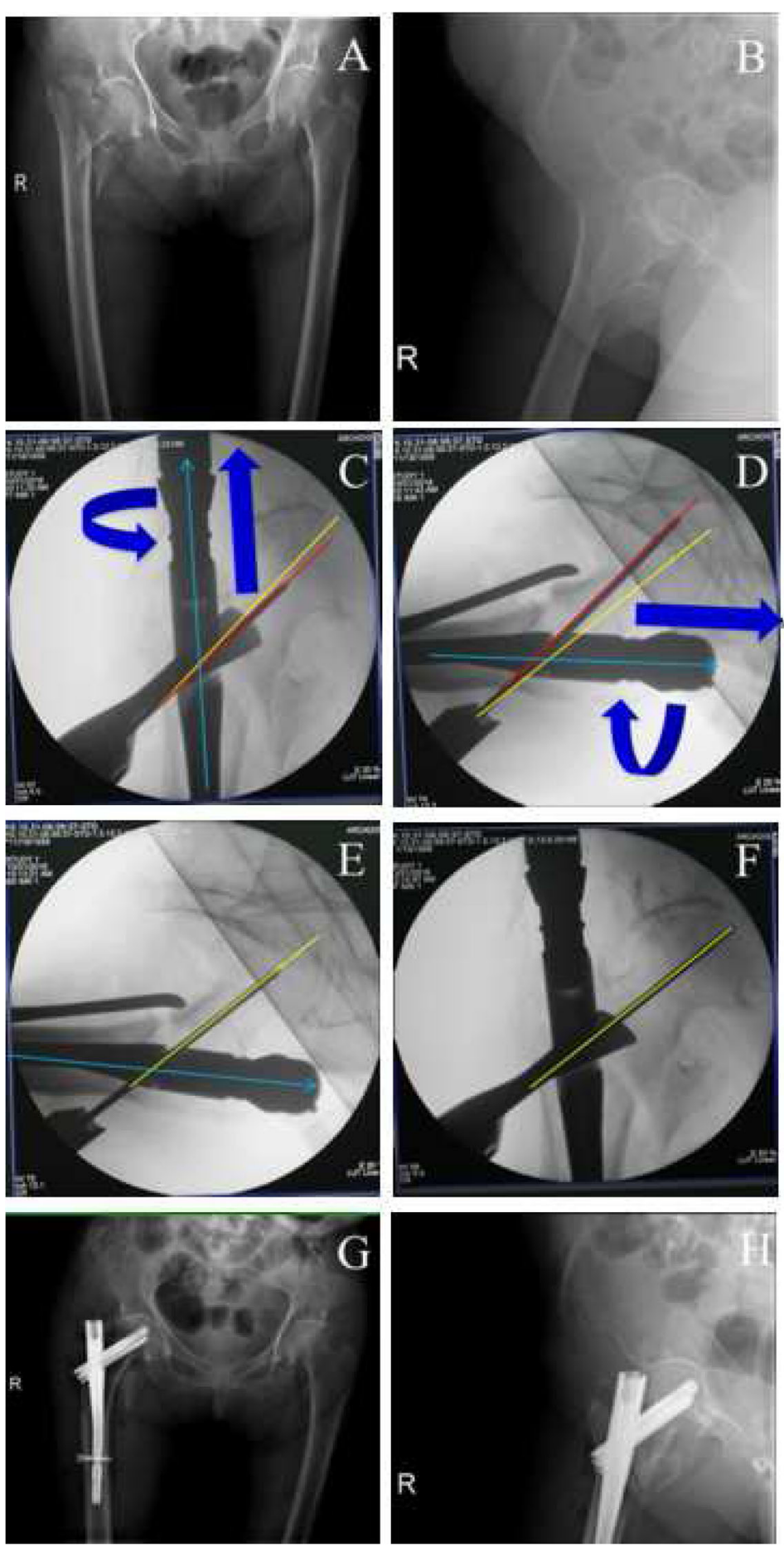

Fig. 5 (See legend on next page.) 
(See figure on previous page.)

Fig. 5 A typical case to regulate the PSA and anteversion angle to obtain ideal TAD. $\mathbf{a}$-b, preoperative anteroposterior (a) and lateral (b) X-ray to diagnose intertaochanteric fractures; $\mathbf{c}-\mathbf{f}$, the adjustment of the guide pin. When position of neck guide pin is lower (the PSA is less, $\mathbf{c}$ ) than normal and anteversion angle of the nail is more than normal $(\mathbf{d})$, we need to partially extract the nail and internally rotate it to make anteversion angle less (f) (at the same time, the PSA will decrease in AP view, e) to get better TAD; $\mathbf{g}-\mathbf{h}$, postoperative anteroposterior ( $\mathbf{g}$ ) and lateral (h) X-ray to confirm the fracture reduction. Green line, nail position; red line, current position; yellow, ideal position

anteversion angle (Figs. 3, 4, 5 and 6), TAD was adjusted to be less than $25 \mathrm{~mm}$ in all patients $(20.52 \pm$ $2.80 \mathrm{~mm}$ ). Fracture reduction (Figs. 3, 4, 5 and 6) was considered good or acceptable in all 50 patients on post-operative radiographs (Table 2).

The mean operative time, fluoroscopy time and length of hospital stay were $65.82 \pm 11.16 \mathrm{~min}, 2.03 \pm$ $0.79 \mathrm{~min}$ and $6.66 \pm 2.49 \mathrm{~d}$. Thirty-one patients received postoperative blood transfusions, with the amount of transfused blood of $3.55 \pm 1.95 \mathrm{U}$ (Table 2). Complication occurred in 6 patients $(10.90 \%)$, including urinary tract infection in $2(4.00 \%)$, bronchopneumonia in 1 (2.00\%), hypoglycemia in 1 (2.00\%), delirium in 2 (4.00\%), uroschesis in 1 (2.00\%), lower limb vein thrombosis in 1 and vulvar ulcerations in 2 (4.00\%) (Table 3). The mean TUG and HHS were $123.60 \pm 12.78 \mathrm{~s}$ and $52.14 \pm 13.78$ postoperatively, $47.52 \pm 27.22 \mathrm{~s}$ and $63.04 \pm 10.72$ at 6 -week, $31.54 \pm$ $20.95 \mathrm{~s}$ and $72.88 \pm 8.79$ at 3 -month follow-up (Table 4).

\section{Model validation}

The curvature radius of the medullary cavity was $90.02 \mathrm{~cm}$. The virtual surgery was realistic with good $3 \mathrm{D}$ visual effects. The design of virtual surgery was in accordance with the actual intraoperative situation. The axis of the main intramedullary nail coincided with the axis of the upper femur. The depth of insertion was proper. The guide pin of tension screw was located at the axis of the femoral neck, and the TAD was $22 \mathrm{~mm}$.

When the main intramedullary nail was externally and internally rotated of $20^{\circ}$ at the standard location, the trajectory of the endpoint of the guide pin was curved. Under the fluoroscopy coordinate system O$\mathrm{XYZ}$, with the axial rotation angle of the main intramedullary nail ( $t)$ as the variable, the changes of the PSA at the anteroposterior position and anteversion angle of the guide pin at the lateral position were observed through calculation (Fig. 7). The PSA at the anteroposterior position and anteversion angle of the guide pin at the lateral position were both increased along with the increase in the $t$ value when the main intramedullary nail was externally rotated (Fig. 7a); while they were decreased along with the decrease in the $t$ value when the main intramedullary nail was internally rotated (Fig. 7b).
According to the correlation between the PSA and the anteversion angle of the guide pin, a personalized position map of the femoral neck guide pin was designed and developed (Fig. 7c). The abscissa was the axial rotation angle of the main intramedullary nail, while the ordinate values were respectively the PSA of guide pin at the anteroposterior position and the anteversion angle of the guide pin at the lateral position. $\mathrm{t}=0$ was defined as the ideal position of the guide pin in the femoral neck. Based on the figure, the PSA of guide pin at the anteroposterior position was $134^{\circ}$, while anteversion angle of the guide pin at the lateral position was $25^{\circ}$ at the corresponding site.

\section{Discussion}

In the present study, we used the CT data of clinical IEF patient series and 3D mathematical model to demonstrate there was a positive correlation between the PSA and the anteversion angle. By synergistically altering the PSA and theanteversion angle, TAD can be easily adjusted to be less than $25 \mathrm{~mm}(20.52 \pm 2.80$ $\mathrm{mm}$ ) which is recommended by several scholars during the fixation of IEFs in order to prevent complications [24, 25]. The accessibility and perfection of TAD adjustment in our study smoothed the surgery (shorter operative time: $65.82 \pm 11.16 \mathrm{~min}$ vs $79.50 \pm$ $21.12 \mathrm{~min}[21,26,27]$ and fluoroscopy time: $2.03 \pm$ $0.79 \mathrm{~min}$ vs $2.9 \pm 0.16 \mathrm{~min}$ ) [7]), improved the treatment effects (higher HHS: range, 57-89 vs 36-97 [28]) and decreased the complications (rate: $12.00 \%$, $6 / 50$ vs $57.44 \%, 108 / 188$ [21]; cut-out: $0 \%$ vs $4 \%$ [29] or $2.7 \%$ [30]) compared with previous studies where TAD was higher than $25 \mathrm{~mm}$, even modified $30 \mathrm{~mm}$ [31] in some cases [28-30].

There was evidence to show the potential correlation between the neck-shaft angle and TAD in IEF patients. For example, Boukebous et al. calculated the neck-shaft angle gap between the fractured and the healthy sides and found the average TAD can reach $27 \mathrm{~mm}$ in patients with a $7 \%$ eck-shaft angle gap rate [32]. Walton et al. demonstrated the number of patients with TAD greater than $25 \mathrm{~mm}$ was more in the group with the neck-shaft angle $<125^{\circ}$ compared to those having the neck-shaft angle $>125^{\circ}(27.8 \%$ vs 12.6\%) [33]. Also, a positive association was observed between the neck-shaft angle and hip position [34, 

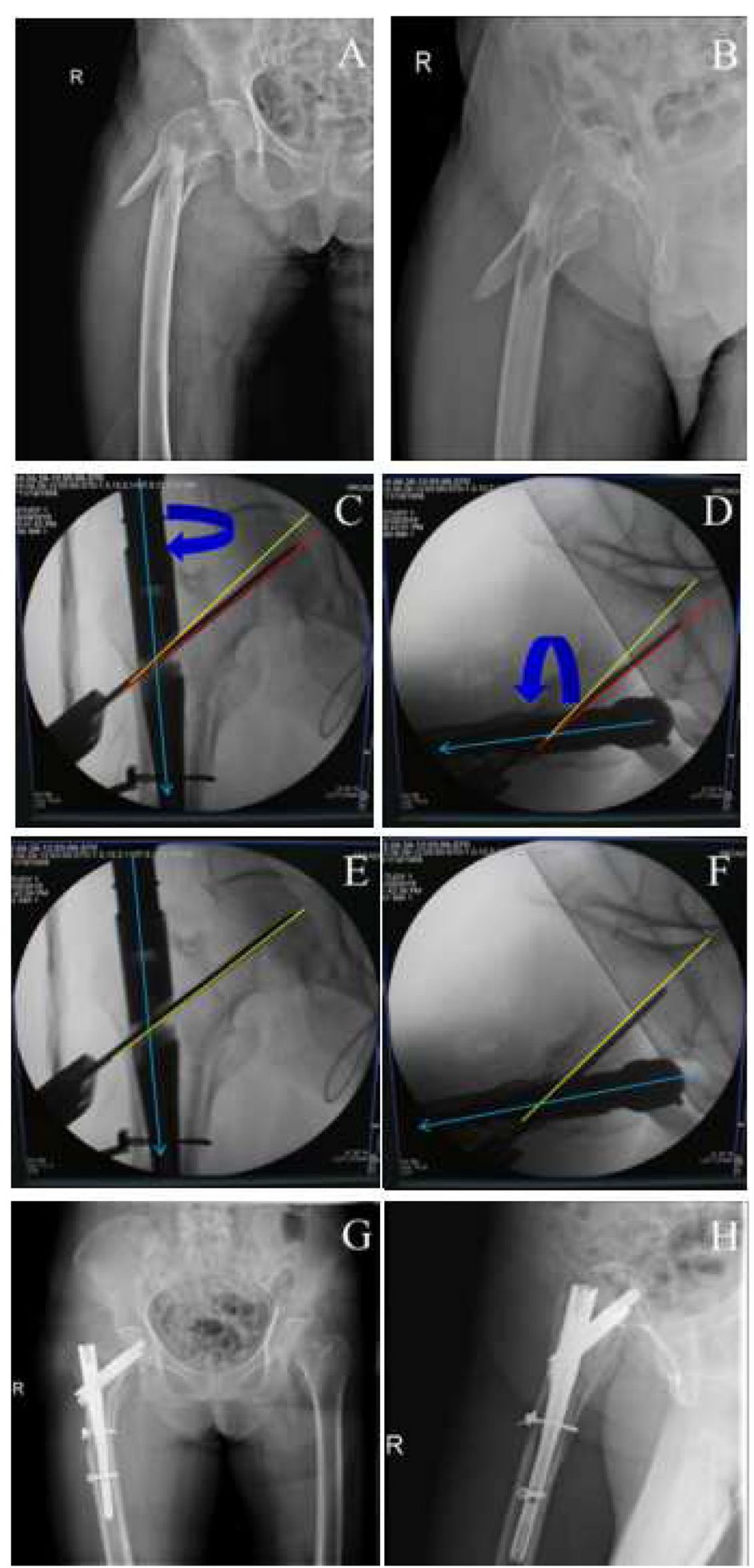

Fig. 6 (See legend on next page.) 
(See figure on previous page.)

Fig. $\mathbf{6}$ A typical case to regulate the PSA and anteversion angle to obtain ideal TAD. $\mathbf{a}$-b, preoperative anteroposterior (a) and lateral (b) X-ray to diagnose intertaochanteric fractures; $\mathbf{c}-\mathbf{f}$, the adjustment of the guide pin. When position of neck guide pin is lower (the PSA is larger, $\mathbf{c}$ ) and anteversion angle of nail is less than normal (d), at first, we need only to externally rotate the nail to make antevertion angle bigger (f) (at the same time, the PSA will become larger in AP view, e) to get better TAD; $\mathbf{g}-\mathbf{h}$, postoperative anteroposterior $(\mathbf{g})$ and lateral (h) X-ray to confirm the fracture reduction. Green line, nail position; red line, current position; yellow, ideal position

35]. However, the role of anteversion angle, as well as its corresponding changes induced by rotation of the nail and how the changes of PSA and anteversion angle to regulate the TAD in IFFs has not been further investigated. Our study was, for the first time, to demonstrate their synergetic relationship and may provide a novel method to quickly regulate TAD in the clinic via the preoperative establishment of the personalized distribution map of femoral neck guide pin (Fig. 7) [36]. But, one thing should be paid attention: the curvature of anterolateral femoral bowing is usually increased in the elderly, which may lead to the mismatching between the cephalomedullary nail and the femur and cause cortical impingement and tail protrusion [37-40]. For these patients, we performed the following procedures to prevent these complications: 1) using the long main nail; 2) the nail entry point should be selected anterior, but not posterior to the greater trochanter; and 3) when the excellent PSA of the guide pin was achieved by rotation of the main nail, the traction force can be slightly elevated. After the TAD was adjusted, the traction force can be restored to the initial level.

However, there were some limitations to this study. First, the application of a personalized distribution map of the femoral neck guide pin must meet the following conditions: 1) The femur at the diseased side has achieved anatomical repositioning. In these patients, the slight rotation of the main mail to change the PSA and the anteversion angle may not influence its reduction stability and affect the position of blade in femoral head (Figs. 4, 5 and 6); 2) Fluoroscopy plane in preoperative simulation surgery should be in accordance with the actual fluoroscopy

Table 3 Postoperative complications

\begin{tabular}{ll}
\hline & Data \\
\hline Urinary tract infection & $2(4.00 \%)$ \\
Bronchopneumonia & $1(2.00 \%)$ \\
Hypoglycemia & $1(2.00 \%)$ \\
Delirium & $2(4.00 \%)$ \\
Uroschesis & $1(2.00 \%)$ \\
Lower limb vein thrombosis & $1(2.00 \%)$ \\
Vulvar ulcerations & $2(4.00 \%)$ \\
\hline
\end{tabular}

during the operation; 3) It fits for adjusting the position of the guide pin in the femoral neck by axial rotation of the main intramedullary nail, but not fit for adjusting the depth of the main intramedullary nail; and 4) The anatomical and fluoroscopy position of the patient must not be changed during fluoroscopy. Second, the experiment design itself also has some limitations. 1) The 3D femoral model in this paper was established based on the patients with preoperative CT scan data and the projection plane may deviate to the actual projection; 2) Engineering software commonly used in digital orthopedics is not designed aiming at orthopedics system, but reference to some mechanical engineering software. When dealing with complex skeleton model, this software may develop some error for the measurement data; 3) Preoperative design and simulation work needs time and improved preoperative imaging tests, which are difficult to apply to patients needing emergency surgery; and 4) the patients were retrospectively enrolled without control and sample size was relatively small and follow up was short, which may result in the underestimation of the complication rate and prognosis. Thus, a prospective study demonstrating the technique intraoperatively will be necessary for the future.

\section{Conclusion}

Through analysis of clinical cases and research on the 3D model, our findings suggest there is a positive correlation between anteversion of the femoral neck guide pin at the lateral position and the PSA of guide pin at the anteroposterior position. When the main intramedullary nail was rotated along the axis

Table 4 Function outcomes

\begin{tabular}{ll}
\hline & Data \\
\hline TUG test (s) & $123.60 \pm 12.78$ \\
Postoperative & $47.52 \pm 27.22$ \\
6-week & $31.54 \pm 20.95$ \\
3-month & \\
Harris Hip Score & $52.14 \pm 13.78$ \\
Postoperative & $63.04 \pm 10.72$ \\
6-week & $72.88 \pm 8.79$ \\
3-month & \\
\hline TUG Timed Up and Go
\end{tabular}




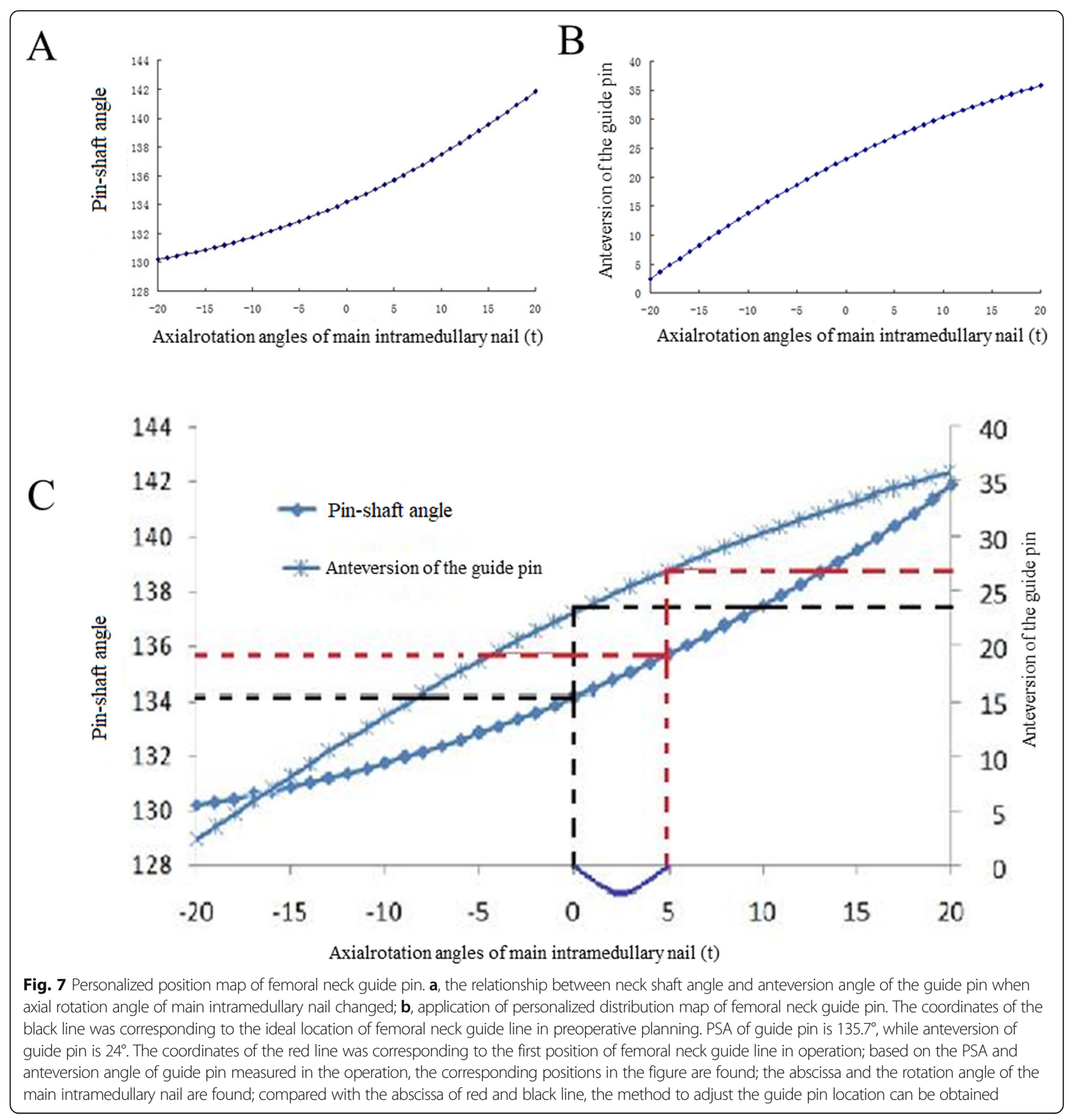

Table 5 Tips for the adjustment of the guide pin

\begin{tabular}{|c|c|c|c|}
\hline Guide pin position (AP) & Anteversion of guide pin (Lateral) & Adjustment protocol & Projection PSA (AP) \\
\hline$\overline{\text { Superior (to ideal position) }}$ & Greater & 1. Decrease the antevertion of nail by intorsion of the nail & Decrease \\
\hline Superior (to ideal position) & Less & $\begin{array}{l}\text { 1. Deepen the nail } \\
\text { 2. Increase the anteversion by extorsion of the nail }\end{array}$ & Increase \\
\hline Inferior (to ideal position) & Greater & $\begin{array}{l}\text { 1. Pull out the nail } \\
\text { 2. Decrease the anteversion of guide pin by the intorsion of the nail }\end{array}$ & Decrease \\
\hline Inferior (to ideal position) & Less & 1. Increase the anteversion of guide pin by the extorsion of the nail & Increase \\
\hline
\end{tabular}


intraoperatively to change the position of the guide pin, as the anteversion of the guide pin was increased, the PSA was also increased. Otherwise, as the anteversion of the guide pin was decreased, the PSA was also decreased. Based on this principle (Table 5), the location of the femoral neck guide pin can be adjusted to get better TAD simply and accurately during operation, which ensures the excellent intraoperative and postoperative outcomes.

\section{Supplementary information}

Supplementary information accompanies this paper at https://doi.org/10. 1186/s12891-020-03518-5.

Additional file 1. Processes of operation simulation and mathematical analysis.

Additional file 2. Patients' data.

\section{Abbreviations}

IFFs: Intertrochanteric femoral fractures; PFNA: Proximal femoral nail antirotation; InterTAN: Proximal femoral nail; TAD: Tip-apex distance; PSA: Pinshaft angle; 3D: Three-dimensional; 2D: Two-dimensional; TUG: Timed Up and Go; HHS: Harris hip score; CT: Computerized tomography; ASA: American Society of Anesthesiologists

\section{Acknowledgements}

None.

\section{Authors' contributions}

$Z W, Y D L, C J L$ and $X T$ participated in conception and design of this study. $Z W, S L L$, and YDL collected the data; ZW and YDL performed the statistical analyses; XHW were involved in interpretation of data. ZW and YDL drafted the manuscript. CJL and XT revised the manuscript for important intellectual content. All authors read and approved the final manuscript.

\section{Funding}

This study was financially supported by Shanghai Municipal Key Specialty Construction Fund of Shanghai Municipal Health Bureau (No. ZK2015A-14). The funders had no role in the study design, collection, analysis or interpretation of the data, writing of the report, or decision to submit the article for publication.

\section{Availability of data and materials}

All data generated or analyzed during this study are included in this published article.

\section{Ethics approval and consent to participate}

This study was approved by ethics committee of the First Affiliated Hospital of Dalian Medical University. All subjects gave a written informed consent to participate in the surgery.

\section{Consent for publication}

All patients gave written consent for publication of images and data.

\section{Competing interests}

The authors declare that they have no conflict of interest.

\section{Author details}

'Department of Orthopedics, Zhongshan Hospital, Fudan University, Shanghai 200032, China. ${ }^{2}$ Department of Orthopedic Trauma, the First Affiliated Hospital of Dalian Medical University, Dalian 116011, Liaoning Province, China. ${ }^{3}$ Department of Bone and Soft Tissue Tumor Surgery, Cancer Hospital of China Medical University Liaoning Cancer Hospital \& Institute, Shenyang 110042, Liaoning Province, China. ${ }^{4}$ Department of Orthopedics, Shanghai University of Medicine \& Health Sciences Affiliated to Zhoupu Hospital, Shanghai 201318, China.
Received: 10 January 2019 Accepted: 20 July 2020

Published online: 01 August 2020

\section{References}

1. Thacker SB, Branche C, Stevens JA, Olson S. Reducing falls and resulting hip fractures among older women. Home Care Provid. 2000;5:134-41.

2. Yoon BH, Lee YK, Kim SC, Kim SH, Ha YC, Koo KH. Epidemiology of proximal femoral fractures in South Korea. Arch Osteoporos. 2013;8:157.

3. Gullberg B, Johnell O, Kanis JA. World-wide projections for hip fracture. Osteoporos Int. 1997;7:407-13.

4. Li AB, Zhang WJ, Wang J, Guo WJ, Wang XH, Zhao YM. Intramedullary and extramedullary fixations for the treatment of unstable femoral intertrochanteric fractures: a meta-analysis of prospective randomized controlled trials. Int Orthop. 2017;41:403-13.

5. Lee YK, Chung CY, Park MS, Lee KM, Koo KH. Intramedullary nail versus extramedullary plate fixation for unstable intertrochanteric fractures: decision analysis. Arch Orthop Trauma Surg. 2013;133:961-8.

6. Ma KL, Wang X, Luan FJ, Xu HT, Fang Y, Min J, Luan HX, Yang F, Zheng H, He SJ. Proximal femoral nails antirotation, gamma nails, and dynamic hip screws for fixation of intertrochanteric fractures of femur: a meta-analysis. Orthop Traumatol Surg Res. 2014;100:859-66.

7. Wu D, Ren G, Peng C, Zheng X, Mao F, Zhang Y. InterTan nail versus Gamma3 nail for intramedullary nailing of unstable trochanteric fractures. Diagn Pathol. 2014;9:191

8. Ma JX, Kuang MJ, Fan ZR, Xing F, Zhao YL, Zhang LK, Chen HT, Han C, Ma $\mathrm{XL}$. Comparison of clinical outcomes with InterTan vs gamma nail or PFNA in the treatment of intertrochanteric fractures: a meta-analysis. Sci Rep. 2017;7:15962.

9. Li S, Chang SM, Niu WX, Ma H. Comparison of tip apex distance and cut-out complications between helical blades and lag screws in intertrochanteric fractures among the elderly: a meta-analysis. J Orthop Sci. 2015;20:1062-9.

10. Kraus M, Krischak G, Wiedmann K, Riepl C, Gebhard F, Jöckel JA, Scola A. Clinical evaluation of PFNA ${ }^{\circledR}$ and relationship between the tip-apex distance and mechanical failure. Unfallchirurg. 2011;114:470-8.

11. Flores SAWA, Caroom C, Jenkins M. The utility of the tip-apex distance in predicting axial migration and cutout with the trochanteric fixation nail system helical blade. J Orthop Trauma. 2016;30:e207-11.

12. Yang JC, Chen HC, Lai YS, Cheng CK. Measurement of tip apex distance and migration of lag screws and novel blade screw used for the fixation of intertrochanteric fractures. PLoS One. 2017;12:e0170048.

13. Yam M, Chawla A, Kwek E. Rewriting the tip apex distance for the proximal femoral nail anti-rotation. Injury. 2017;48:1843-7.

14. Regling M, Blau A, Probe RA, Maxey JW, Solberg BD. Improved lag screw positioning in the treatment of proximal femur fractures using a novel computer assisted surgery method: a cadaveric study. BMC Musculoskelet Disord. 2014;15:189

15. Johnson L, Cope MR, Shahrokhi S, Tamblyn P. Measuring tip-apex distance using a picture archiving and communication system (PACS). Injury. 2008;39. 786-90.

16. Quah C, Mehta R, Shivji FS, Hassan S, Chandrasenan J, Moran CG, Forward $D P$. The effect of surgical experience on the amount of radiation exposure from fluoroscopy during dynamic hip screw fixation. Ann R Coll Surg Engl. 2017:99:198-202.

17. Sakagoshi D, Sawaguchi T, Shima Y, Inoue D, Oshima T, Goldhahn S. A refined definition improves the measurement reliability of the tip-apex distance. J Orthop Sci. 2016;21:475-80.

18. Wright J, Kahane S, Moeed A, Macdowell A. Accuracy of the surgeon's eye: use of the tip-apex distance in clinical practice. Injury. 2015;46:1346-8.

19. Kuhl M, Beimel C. Enhanced cephalomedullary nail lag screw placement and intraoperative tip-apex distance measurement with a novel computer assisted surgery system. Injury. 2016;47:2155-60.

20. Li S, Chang SM, Jin YM, Zhang YQ, Niu WX, Du SC, Zhang LZ, Ma H. A mathematical simulation of the tip-apex distance and the calcar-referenced tip-apex distance for intertrochanteric fractures reduced with lag screws. Injury. 2016;47:1302-8.

21. Li J, Cheng L, Jing J. The Asia proximal femoral nail antirotation versus the standard proximal femoral antirotation nail for unstable intertrochanteric fractures in elderly Chinese patients. Injury. 2015:101:143-6.

22. Morris $S$, Morris ME, lansek R. Reliability of measurements obtained with the timed "up \& go" test in people with Parkinson disease. Phys Ther. 2001; 81(2):810-8 
23. Harris WH. Traumatic arthritis of the hip after dislocation and acetabular fractures: treatment by Moore arthroplasty. J Bone Joint Surg Am. 1969; 51(4):737-55.

24. Baumgaertner MR, Curtin SL, Lindskog DM, Keggi JM. The value of the tipapex distance in predicting failure of fixation of peritrochanteric fractures of the hip. J Bone Joint Surg Am. 1995;77:1058-64.

25. Rubio-Avila J, Madden K, Simunovic N, Bhandari M. Tip to apex distance in femoral intertrochanteric fractures: a systematic review. J Orthop Sci. 2013; 18:592-8.

26. Li AB, Zhang WJ, Wang JQ, Zhao YM, Guo WJ. Learning curve and clinical outcomes of performing surgery with the InterTan intramedullary nail in treating femoral intertrochanteric fractures. Biomed Res Int. 2017;2017: 6781070.

27. Mark RBI, Ruurd L. Intramedullary hip screw Wxation of reverse oblique and transverse trochanteric femur fractures. Eur J Orthop Surg Traumatol. 2008; 18:323-6.

28. Duramaz A, Ilter MH. The impact of proximal femoral nail type on clinical and radiological outcomes in the treatment of intertrochanteric femur fractures: a comparative study. Eur J Orthop Surg Traumatol. 2019;29:1441-9.

29. Gavaskar AS, Tummala NC, Srinivasan P, Gopalan H, Karthik B, Santosh S. Helical blade or the integrated lag screws: a matched pair analysis of 100 patients with unstable trochanteric fractures. J Orthop Trauma. 2018:32:274-7.

30. Mallya S, Kamath SU, Madegowda A, Krishnamurthy SL, Jain MK, Holla R. Comparison of radiological and functional outcome of unstable intertrochanteric femur fractures treated using PFN and PFNA-2 in patients with osteoporosis. Eur J Orthop Surg Traumatol. 2019:29:1035-42.

31. Nikoloski AN, Osbrough AL, Yates PJ. Should the tip-apex distance (TAD) rule be modified for the proximal femoral nail antirotation (PFNA)? A retrospective study. J Orthop Surg Res. 2013;8:35.

32. Boukebous B, Flouzat-Lachaniette CH, Donadio J, Chenguel Z, Guillon P, Rousseau MA. Femoral offset loss and internal arch restoration defect are correlated with intramedullary nail cut-out complications after pertrochanteric fractures: a case-control study. Eur J Orthop Surg Traumatol. 2019;29:1451-60.

33. Walton NP, Wynn-Jones H, Ward MS, Wimhurst JA. Femoral neck-shaft angle in extra-capsular proximal femoral fracture fixation; does it make a TAD of difference? Injury. 2005;36(11):1361-4.

34. Bhashyam AR, Rodriguez EK, Appleton P, Wixted JJ. The effect of hip positioning on the projected femoral neck-shaft angle: a modeling study. J Orthop Trauma. 2018;32(7):e258-62.

35. Kay RM, Jaki KA, Skaggs DL. The effect of femoral rotation on the projected femoral neck-shaft angle. J Pediatr Orthop. 2000;20(6):736-9.

36. Aros B, Tosteson A, Gottlieb DJ, Koval KJ. Is a sliding hip screw or IM nail the preferred implant for intertrochanteric fracture fixation? Clin Orthop Relat Res. 2008:466:2827-32

37. Roberts JW, Libet LA, Wolinsky PR. Who is in danger? Impingement and penetration of the anterior cortex of the distal femur during intramedullary nailing of proximal femur fractures: preoperatively measurable risk factors. J Trauma Acute Care Surg. 2012;73(1):249-54.

38. Peña OR, Gómez Gélvez A, Espinosa KA, Cardona JR. Cephalomedullary nails: factors associated with impingement of the anterior cortex of the femur in a Hispanic population. Arch Orthop Trauma Surg. 2015;135(11): 1533-40.

39. Chang SM, Hu SJ, Ma Z, Du SC, Zhang YQ. Femoral intertrochanteric nail (fitn): a new short version design with an anterior curvature and a geometric match study using post-operative radiographs. Injury. 2018;49(2): 328-33.

40. Zhang K, Zhang S, Yang J, Dong W, Wang S, Cheng Y, Alqwbani M, Wang $\mathrm{Q}$, Yu B. Proximal femoral nail vs. dynamic hip screw in treatment of intertrochanteric fractures: a meta-analysis. Med Sci Monit. 2014;20:1628-33.

\section{Publisher's Note}

Springer Nature remains neutral with regard to jurisdictional claims in published maps and institutional affiliations.

\section{Ready to submit your research? Choose BMC and benefit from:}

- fast, convenient online submission

- thorough peer review by experienced researchers in your field

- rapid publication on acceptance

- support for research data, including large and complex data types

- gold Open Access which fosters wider collaboration and increased citations

- maximum visibility for your research: over $100 \mathrm{M}$ website views per year

At BMC, research is always in progress.

Learn more biomedcentral.com/submissions 